\title{
Demand robust counterpart open capacitated vehicle routing problem time windows and deadline model of garbage transportation with LINGO 13.0
}

Fitri Maya Puspita, Ani Sahara Br. Simanjuntak, Rima Melati, Sisca Octarina

Department of Mathematics, Faculty of Mathematics and Natural Sciences, Sriwijaya University, Indonesia

\begin{tabular}{|c|c|}
\hline Article Info & ABSTRACT \\
\hline Article history: & Demand robust counterpart-open capacitated vehicle routing problem with \\
\hline Received Dec 9, 2019 & $\begin{array}{l}\text { time windows and deadline (DRC-OCVRPtw,d) model formed and explained } \\
\text { in this paper, is the model used to find the minimum distance and the time }\end{array}$ \\
\hline Revised May 20, 2020 & needed for vehicles to transport garbage in Sukarami Sub-District, \\
\hline Accepted May 31, 2020 & $\begin{array}{l}\text { Palembang that consists of the time it takes for the vehicle to pass through } \\
\text { the route. Time needed to transport garbage to the vehicle is called time }\end{array}$ \\
\hline Keywords: & $\begin{array}{l}\text { windows. Combination of the thoses times is called deadline. The farther } \\
\text { the distance passed by vehicle and the more garbage transported, the longer }\end{array}$ \\
\hline Deadline & the deadline is needed. This DRC-OCVRPtw, d model is completed by \\
\hline Demand robust & LINGO 13.0 to obtain the optimal route and time deadline for Sukarami \\
\hline Demand rooust & Sub-District. The model shows that the improved model of open vehicle \\
\hline Garbage & routing problem involving the robustness, time windows and deadline can \\
\hline Time windows & achieve the optimal routes that enable driver to save operational time in \\
\hline Transportation OCVRP & $\begin{array}{l}\text { picking up the garbage compared to similar problem not involving no-time } \\
\text { windows and deadline stated in previous research. }\end{array}$ \\
\hline
\end{tabular}

Copyright $@ 2020$ Institute of Advanced Engineering and Science. All rights reserved.

\section{Corresponding Author:}

Fitri Maya Puspita,

Department of Mathematics, Faculty of Mathematics and Natural Sciences,

Sriwijaya University,

Palembang-Prabumulih Highway, KM 32 Inderalaya Ogan Ilir 30662 South Sumatera, Indonesia.

Email: pipitmac140201@gmail.com

\section{INTRODUCTION}

The city of Palembang is one of the big city in Indonesia that has high population density. Because of the high population density in the city of Palembang, this has result in increased garbage production. While the transportation of garbage in Palembang city is less effective resulting in garbage accumulation occurring. To overcome this garbage accumulation problem, a more effective and efficient waste transportation system is needed. This kind of problem can be solved as a network [1]. So that it can minimize the distance to be traveled and the time needed to complete the garbage transportation.

There are two types of garbage cars used, namely armroll and dump truck. The capacity of garbage that can be transported by amroll and dump trucks is 4 tons. The optimal route to be determined is the distance $[2,3]$ from several TWDs (temporary waste disposal) to final waste disposal (FWD) in the form of a vehicle routing problem (VRP) $[4,5]$ model . In addition, VRP is also used to minimize transportation costs and the time needed for vehicles to transport waste [6]. In this case, the vehicle will transport waste from each TDW then the waste will be brought to FDW. Vehicles in Sukarami Sub-District have a fixed capacity with a single commodity, so-called capacitated vehicle routing problems (CVRP) [7, 8]. Application of CVRP is an application relating to the retrieval and delivery of goods, where the capacity of goods is limited and remains a special feature of the CVRP model [9-13].

The transportation system in Sukarami Sub-District is divided into 6 working areas (WA). Every WA has one garbage truck. In this case, After transported garbage from TWD and to be brought to 
FWD, the vehicle is not returned to the environmental and hygiene services (EHS) Palembang but the vehicle is brought by the driver to their respective homes. Therefore, that the work is easier and more effective and vehicle route becomes more efficient. So that garbage transportation in the Sukarami Sub-District used the open vehicle routing problem (OCVRP) [7, 14], where the route passed does not form a closed route but forms an open route. If the route is not closed, so the driver can start anywhere from point so this problem has uncertainty, where the results will obtained vary greatly. Of course, among those results, one result is the best solution. This uncertainty is defined as the demand robust counterpart (DRC) model [15-17]. DRC model is expected to solve the uncertainty where in this case, the uncertainty is the volume of garbage at each TDW. This DRC model can be solved by LINGO 13.0 application.

The drawbacks of those previous researches focused on DRC model were lack of information about time search formula needed by the vehicle and no time limit to travel for each TWD. In fact, for garbage transportation in Palembang recently, the real situation does not fit the condition of DRC model only. It needs the improved model to fit the real condition occurring in transporting garbage. Added parameters such as time that it takes the vehicle to pass through all garbage transport points and the time needed to move waste from TWD to the vehicle is called time windows [6, 18, 19]. Other parameter which is deadline [20-22] means time that takes a vehicle to complete garbage transport.

Based on those drawbacks above, it is a critical need for rearranging and designing the optimal route as new improved formulation for transporting the garbage under demand robustness with added parameters namely time windows and deadline (DRC-OCVRPtw,d ) to meet the real condition occurring in garbage transportation nowadays. The performance of the new model will be compared in terms of cost gained with previous model [17] without added parameter included. The model proposed is not only helping the agency in finding the optimal routes but also saving the operational cost [23-25] for each day travelled to pick up the garbage.

\section{RESEARCH METHOD}

The distance data is obtained from EHS Palembang, where Sukarami Sub-District, Palembang was chosen as one the crowded area in Palembang. Besides that, a survey and direct observation were also carried out to check the distance from TWD to TWD, FWD to TWD, and TWD to FWD. The data is also gathered by direct interviews with garbage truck drivers. The data obtained is in form of a vehicle being driven at a speed of $30 \mathrm{~km} /$ hour. As for the time of garbage transportation, to transport 2 tons of garbage to the truck will takes 1 hour. Then, steps to complete the DRC-OCVRPtw,d model are as following.

- Collect data in the form of: the number of cars operating in the Sukarami along with the volume of vehicle capacity, the route through each vehicle and the volume transported from each TWD, the distance traveled from the between TWD, and TWD to FWD. The average speed of the vehicle must also be known when carrying out garbage transportation, as well as an estimate of how long it takes the janitor to move waste from the TWD to the truck.

- Form the distance data for each working area in the Sukarami Sub-District into tables. The tables are called the distance matrix tables.

- Model and design the new improved model of DRC-OCVRPtw,d by collecting all the distance data, garbage volume data at every TWD into the DRC Model that has been formed into the time search formula in the model.

- Input the model into the LINGO 13.0 application. The method used in LINGO 13.0 is the Branch and Bound method. LINGO 13.0 displays the optimal solution, the time deadline, the route to be passed by vehicle, time needed to pass all routes and the time needed to transport garbage to vehicle (tw) with addition deadline (d) for each working area.

- Performance evaluation is done by comparing with previous routes without added parameter and then form the model for each work area in the Sukarami Sub-District and make a route map for each work area.

\section{RESULTS AND DISCUSSION}

In Sukarami Sub-District Palembang, each garbage transport vehicle is divided into every working areas that are provided by 6 garbage transport vehicles in with capacity of every vehicle 4 tons. Therefore, there are 6- working area in Sukarami Subdistrict. The vehicle types, TWD location, TWD capacity and Garbage volume in every WA in Sukarami Sub-District are explained in Table 1. Table 2 explains one of the distance table in $6 \mathrm{WA}$ in Sukarami that is WA 1. The distances are measured in $\mathrm{km}$. 
Table 1 . The vehicle types, TWD location, TWD capacity and garbage volume in every WA in Sukarami Sub-District

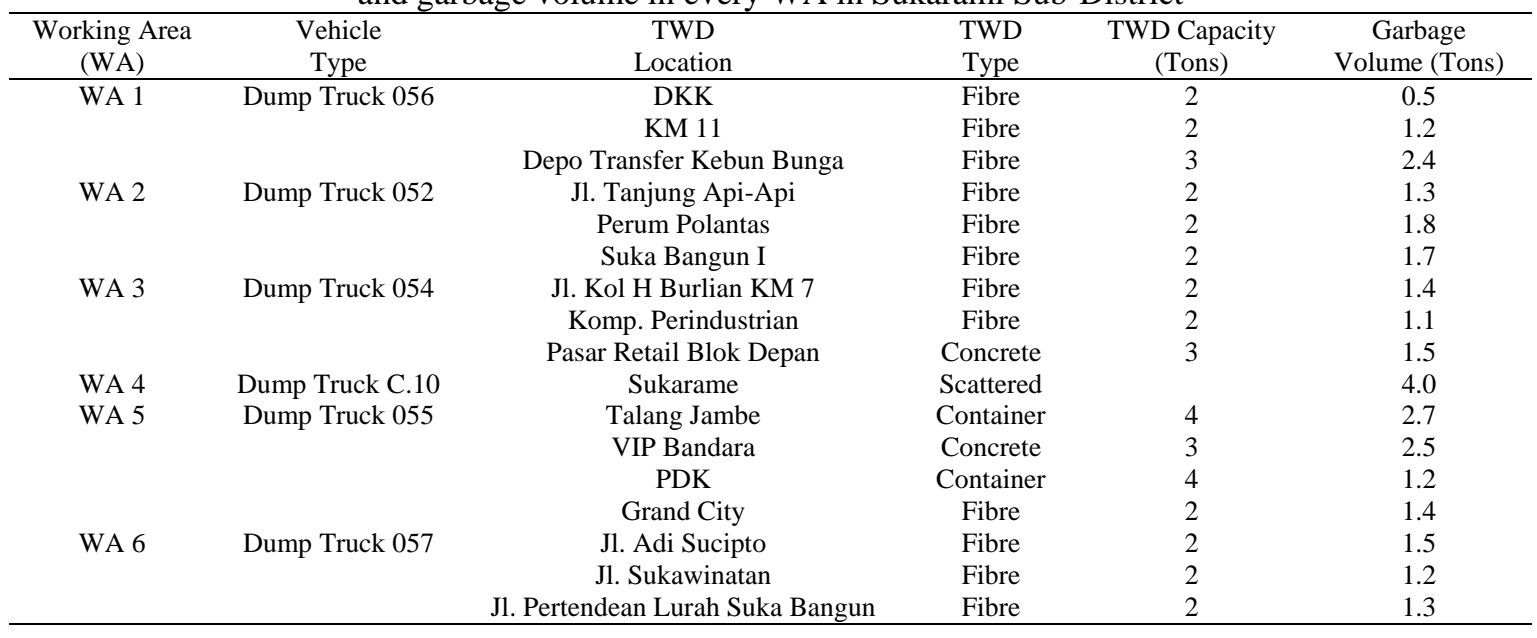

Source: EHS (environmental and hygiene services) Palembang

Table 2. Distance among FWD and TWDs in WA 1 Sukarami Sub-District

\begin{tabular}{ccccc}
\hline & FWD & 1 & 2 & 3 \\
\hline FWD & 0 & 13.2 & 19.42 & 19.58 \\
1 & 13.2 & 0 & 3.4 & 4.2 \\
2 & 19.42 & 3.4 & 0 & 5.39 \\
3 & 19.58 & 4.2 & 5.39 & 0 \\
\hline
\end{tabular}

with Karya Jaya FWD

1. DKK TWD

2. KM 11 TWD

3. Kebun Bunga TWD

The improved model as DRC-OCVRP ${ }_{t w, d}$ model is designed as follows. This Model consists of a combination of the DRC Model and OCVRP Model and time formula.

$$
\operatorname{Min} z=\sum_{i \epsilon S} c_{0 i} y_{0 i}+c_{i 0} y_{i 0}+\sum_{i, j \in S} c_{i j} x_{i j}
$$

Subject to

$$
\begin{aligned}
& \sum_{i, j \in S} y_{0 i}+y_{i 0}+x_{i j} \geq 1 \text { for all }(i=1,2, \ldots n) \\
& \sum_{i \epsilon S} y_{0 i}+\sum_{i, j \epsilon S} x_{i j} \geq K(s) \\
& \sum_{i \epsilon S} y_{i 0}+\sum_{i, j \epsilon S} x_{i j} \geq K(s) \\
& d_{i} \leq l_{i} \leq Q \quad \forall i \epsilon S \backslash\{0\} \\
& l_{i}-l_{j}+Q x_{i j} \leq Q-d_{j} \quad \forall i, j \in A, i \neq 0, j \neq 0 \\
& V \geq 0 \\
& k \geq 0 \\
& t w_{0 i}=\frac{c_{0 i}}{v} \\
& t w_{i 0}=\frac{c_{i 0}}{v}+\frac{l_{i}}{k}
\end{aligned}
$$




$$
\begin{aligned}
& t w_{i j}=\frac{c_{i 0}}{v}+\frac{l_{j}}{k} \\
& d=\sum_{i \epsilon S} t w_{0 i}+t w_{i 0}+\sum_{i, j \in S} t w_{i j} \\
& x_{i j} \in\{0,1\} \text { for }(1 \leq i \leq j \leq n) \\
& y_{0 i} y_{i o} \in\{0,1\}(i=1,2, \ldots, n) \\
& t w_{i j}, t w_{0 i}, t w_{i o} \geq 0(1 \leq i \leq j \leq n)
\end{aligned}
$$

With parameters defined are as follows.

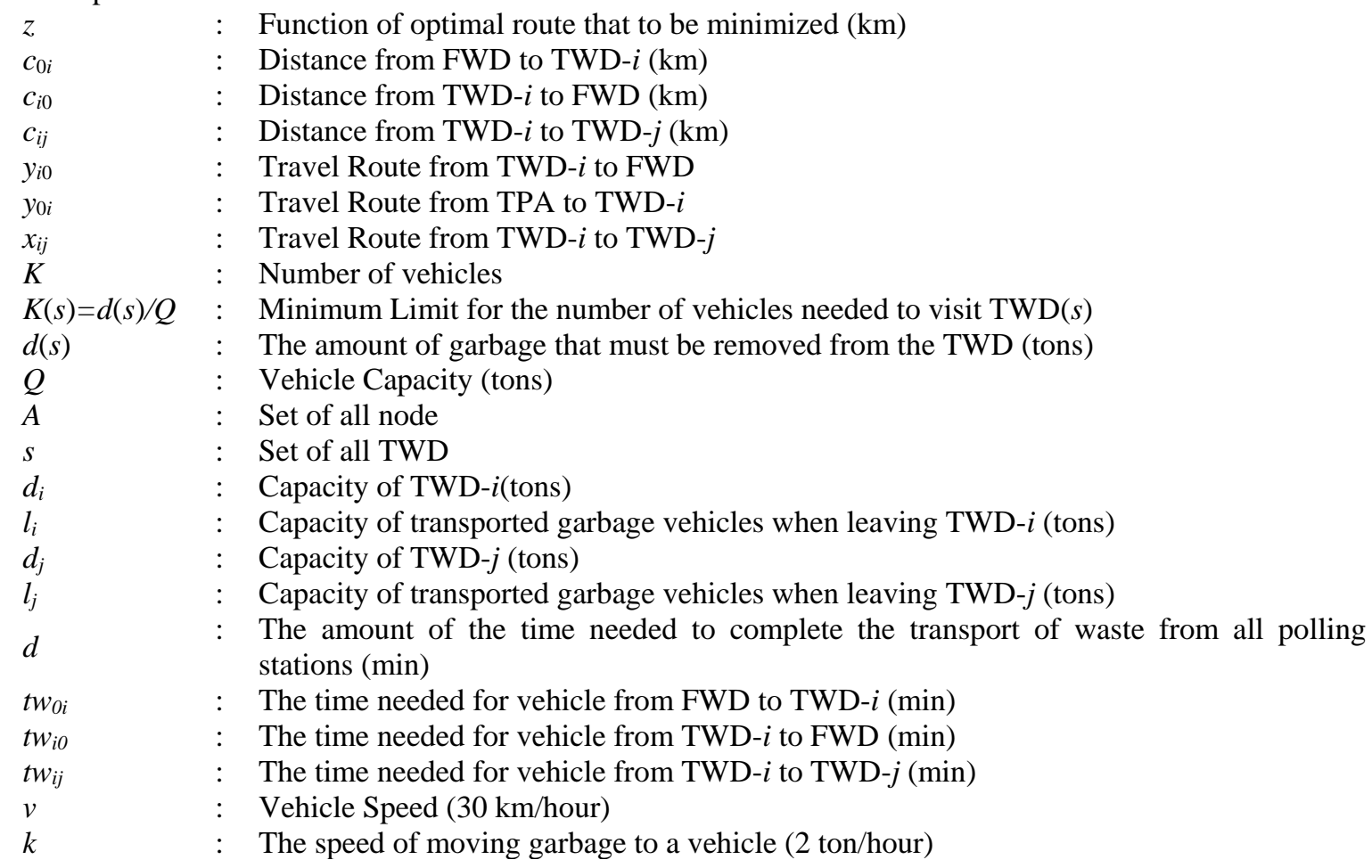

The above model is an DRC-OCVRP ${ }_{t w, d}$ model, which is a combination of the robust counterpart model and OCVRP model and added a formula to find time in the model. The above model is used to find the minimum distance of waste transportation routes and the time needed to complete garbage transportation. The time needed for the vehicle to cross the route and the time needed by the officer to move the garbage to the truck bed is called time windows ( $t w)$.

For the WA 1 model then

$$
K(s)=\frac{0.3+1.2+2.4}{4}=\frac{3.9}{4}=0.975
$$

Next, Minimum $z=$

$$
\begin{aligned}
& 13.2 y_{01}+19.42 y_{02}+19.58 y_{03}+13.2 y_{10}+3.4 x_{12}+4.2 x_{13}+19.42 y_{20}+3.4 x_{21}+5.39 x_{23}+ \\
& 19.58 y_{30}+4.2 x_{31}+5.39 x_{32}
\end{aligned}
$$

Subject to

$$
\begin{aligned}
& y_{01}+x_{12}+x_{13}+y_{10} \geq 1 \\
& y_{02}+x_{21}+x_{23}+y_{20} \geq 1 \\
& y_{03}+x_{31}+x_{32}+y_{30} \geq 1
\end{aligned}
$$




$$
\begin{aligned}
& y_{01}+y_{02}+y_{03}+x_{12}+x_{13}+x_{21}+x_{23}+x_{31}+x_{32} \geq 0.975 \\
& y_{10}+y_{20}+y_{30}+x_{12}+x_{13}+x_{21}+x_{23}+x_{31}+x_{32} \geq 0.975 \\
& 300 \leq l_{1} \leq 4000 \\
& 1200 \leq l_{2} \leq 4000 \\
& 2400 \leq l_{3} \leq 4000 \\
& l_{1}-l_{2}+4000 x_{12} \leq 2800 \\
& l_{1}-l_{3}+4000 x_{13} \leq 1600 \\
& l_{2}-l_{1}+4000 x_{21} \leq 3700 \\
& l_{2}-l_{3}+4000 x_{23} \leq 1600 \\
& l_{3}-l_{1}+4000 x_{31} \leq 3700 \\
& l_{3}-l_{2}+4000 x_{32} \leq 2800 \\
& y_{01}, y_{02}, y_{03}, x_{12}, x_{13}, x_{21}, x_{23}, x_{31}, x_{32} \geq 0
\end{aligned}
$$

Because the route obtained is not valid, then the addition of balancing of constraints are needed. Constraint $y_{03}+x_{31}+x_{32}+y_{30} \geq 1$ can be reformulated into $x_{32}=1$. After the route is obtained, then add time windows and deadline parameters based on the route that has been obtained. Therefore, the model can be added as follows.

$$
\begin{aligned}
& v \leq 30 \\
& k \leq 4000 / 120 \\
& t w_{32}=\frac{5.39}{v}+\frac{2400}{k} \\
& t w_{21}=\frac{3.4}{v}+\frac{1200}{k} \\
& t w_{10}=\frac{13.2}{v}+\frac{300}{k} \\
& d=t w_{32}+t w_{21}+t w_{10}
\end{aligned}
$$

The model is solved by using LINGO 13.0 to obtain the decision variables as depicted in Table 3 .

Table 3. DRC-OCVRP ${ }_{t w, d}$ solution for working area 1 in Sukarami Sub-District

\begin{tabular}{cccc}
\hline Variable & WA 1 & Variable & WA 1 \\
\hline$z$ & 21.99 & $x_{31}$ & 0 \\
$y_{01}$ & 0 & $x_{32}$ & 1 \\
$y_{02}$ & 0 & $l_{1}$ & 300 \\
$y_{03}$ & 0 & $l_{2}$ & 1200 \\
$y_{10}$ & 2 & $l_{3}$ & 2400 \\
$x_{12}$ & 0 & $t w_{32}$ & 82.78 minutes \\
$x_{13}$ & 0 & $t w_{21}$ & 42.8 minutes \\
$y_{20}$ & 0 & $t w_{10}$ & 35.4 minutes \\
$x_{21}$ & 1 & $d$ & 160.98 minutes \\
$x_{23}$ & 0 & $v$ & $30 \mathrm{~km} / \mathrm{jam}$ \\
$y_{30}$ & 0 & $k$ & 33.33 \\
\hline
\end{tabular}


Sukarami Sub-District has 3 TWDs with 1 vehicle used to transport waste from 3 TWDs. Table 3 is the solution to the search for waste transportation routes in working area 1 by using LINGO 13.0. Variable with value of 1 means that the route is passed, while variables with value of 0 are not passed. Minimum distance obtained was of $21.99 \mathrm{~km}$ with a deadline time of 160.98 minutes or 2 hours 41 minutes as Table 3 explained. Figure 1 depicts the optimal route for transportation of waste, starting from Kebun Bunga TWD - KM 11 TWD - Karya Jaya FWD - DKK TWD - Karya Jaya FWD. If compared with research from Puspita et al [1], there are different results due to additional FWD recently and updated the distance and volume of waste. Table 4 displays the results for 6 WA in Sukarami by LINGO 13.0.

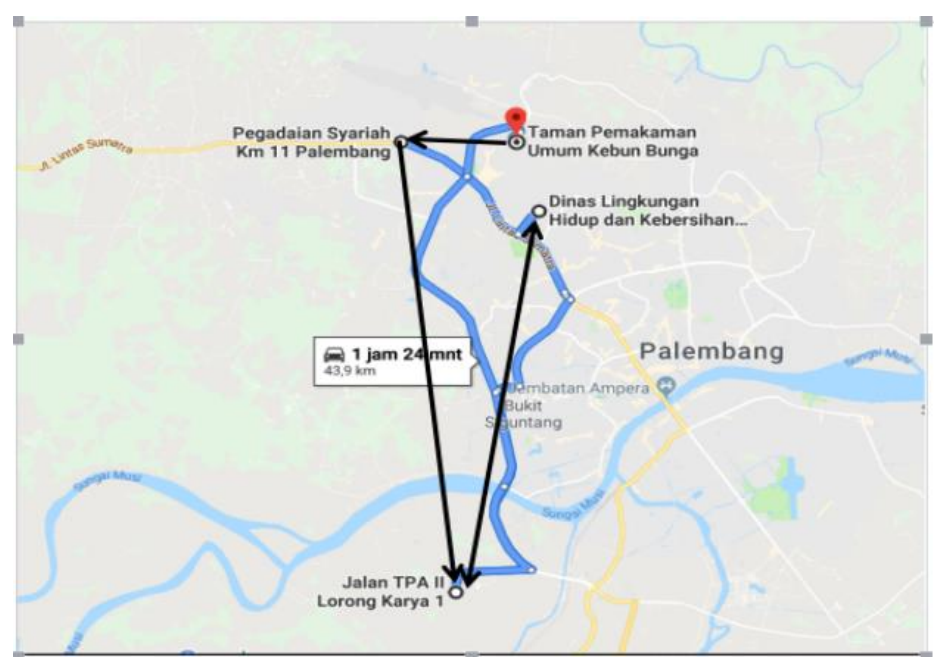

Figure 1. WA 1 in Sukarami Sub-District

Table 4. Solution of DRC-OCVRP ${ }_{\mathrm{tw}, \mathrm{d}}$ in Sukarami Sub-Districts

\begin{tabular}{|c|c|c|c|c|c|c|}
\hline \multirow[t]{2}{*}{ Solver Status } & \multicolumn{6}{|c|}{ Working Area } \\
\hline & 1 & 2 & 3 & 4 & 5 & 6 \\
\hline Model Class & \multicolumn{6}{|c|}{ MLP } \\
\hline State & \multicolumn{6}{|c|}{ Optimal Global } \\
\hline Objective & 21.99 & 55.95 & 58.57 & 24.07 & 77.66 & 34.37 \\
\hline Infeasibility & 0 & 0 & 0 & 0 & 0 & 0 \\
\hline Iterations & 12 & 0 & 0 & 0 & 0 & 0 \\
\hline \multirow{2}{*}{ Deadline } & 2 hours & 4 hours & 4 hours & 3 hours & 6 hours & 3 hours \\
\hline & 41 minutes & 16 minutes & 22 minutes & 37 minutes & 29 minutes & 9 minutes \\
\hline
\end{tabular}

Then, the optimal route for other 5 WA is described in Figure 2(a) to 2(e) (see in Appendix). From the calculation using the LINGO 13.0 application, the following results are obtained as Table 4 explained. The longest time deadline is achieved in WA 3 with 4 hours and 22 minutes while the shortest one is within 3 hours 9 minutes. The differences in deadline are due to how many TWDs and the areas covered. WA 1 involves quite many TWDs that is why it takes quite some time to finish the routes. So the farther the distance and the more volume of waste, the more time is needed to complete the transport of garbage. The objective function value shows the optimal routes obtained with the additional value of time windows and deadline needed for each working area. Figure 2 explained all other 5 routes in Sukarami. Those figures show the direct arcs from each TWD to FWD.

\section{CONCLUSION}

The models designed is aimed to have more optimal routes for EHS in Palembang to decide in saving the operational cost. The results shown that the more FWDs the longer times to finish the routes shown by the deadline. The model is calculated exactly by using LINGO 13.0 to show the optimal routes. However, due to some assumption on traffics since the focus of robustness is in terms of demand for each TWD, then for further research perhaps can extend into the robustness in dealing with time traveled to pick up the garbage. 


\section{APPENDIX}

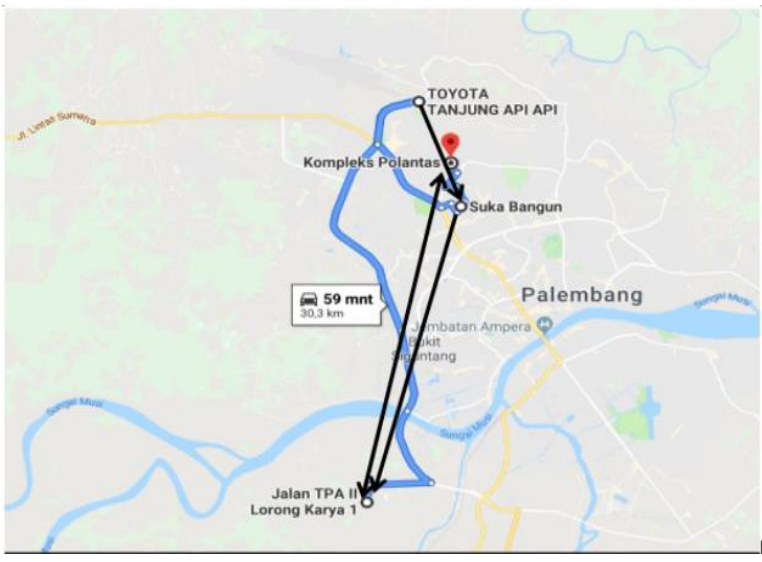

(a)

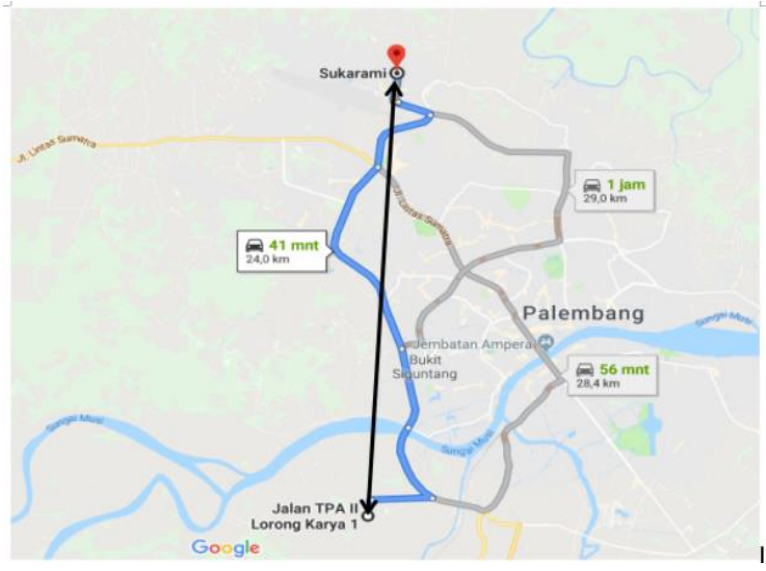

(c)

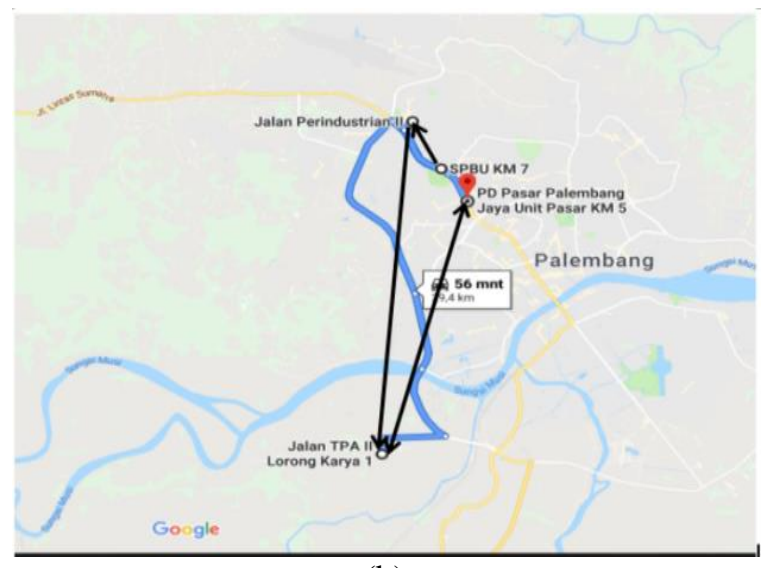

(b)

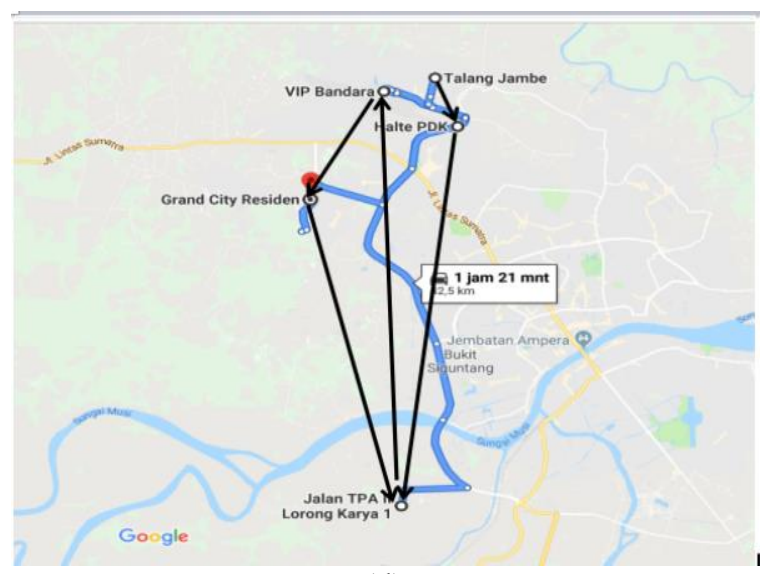

(d)

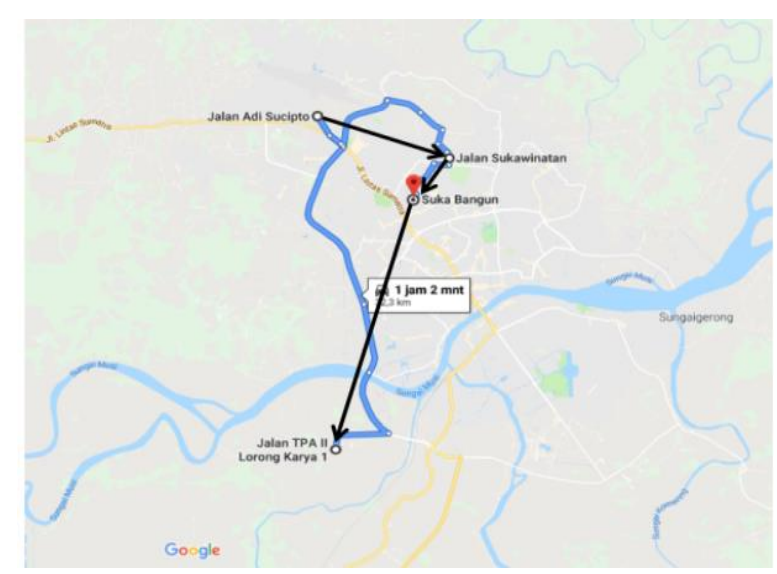

(e)

Figure 2. The other 5 routes in Sukarami Sub-District (a) for WA 2, (b) for WA 3, (c) for WA 4, (d) for WA 5, (e) for WA 6

\section{ACKNOWLEDGEMENTS}

The research is funded by Directorate oh Higher Education of Indonesia through Penelitian Dasar Unggulan Perguruan Tinggi Year 2019. 


\section{REFERENCES}

[1] K. Swamy S., et al., "Design and implementation of secured agent based NOC using shortest path routing algorithm," International Journal of Electrical and Computer Engineering (IJECE), vol. 9, no. 2, pp. 950-959, 2019.

[2] E. Yuliza and F. M. Puspita, "The Branch and Cut Method for Solving Capacitated Vehicle Routing Problem (CVRP) Model of LPG Gas Distribution Routes," Science and Technology Indonesia, vol. 4, no. 4, pp. 105-108, 2019.

[3] A. N. Letchford, et al., "A branch and cut algorithm for the capacitated open vehicle routing problem," Journal of the Operational Research Society, vol. 58, no. 12, pp. 1642-1651, 2007.

[4] K. Braekers, et al., "The vehicle routing problem: State of the art classification and review," Computers and Industrial Engineering, vol. 99, pp. 300-313, 2016

[5] Z. Borcinova and S. Pesko, "The lexicographical capacitated vehicle routing problem," 2017 IEEE International Conference on Service Operations and Logistics, and Informatics (SOLI), Bari, Italy, 2017.

[6] A. Agra, et al., "The robust vehicle routing problem with time windows," Computers and Operations Research, vol. 40, no. 3, pp. 856-866, 2013

[7] S. N. Kumar and R. Panneerselvam, "A survey on the vehicle routing problem and its variants," Intelligent Information Management, vol. 4, no. 3, pp. 66-74, 2012.

[8] I. Sungur, et al., "A robust Optimization Approach for the capacitated Vehicle Routing Problem with demand uncertainty," IIE Transactions, vol. 40, no. 5, pp. 509-523, 2008.

[9] F. Baouche, et al., "Electric vehicle shortest path problem with replenishment constraint," 2014 International Conference on Connected Vehicles and Expo (ICCVE), Vienna, Austria, 2014.

[10] E. Yuliza, et al., "Solution of Capacitated Vehicle Routing Problem Using Branch and Cut Method and Clarke and Wright Algorithm for Determining LPG Gas Distribution Routes," 2nd International Conference on Science and Technology (ICST), 2019. [Online], Available: http://semiratathe2ndicst.fmipa.unib.ac.id/.

[11] C. C. Yeh, et al., "Two-Stage Iterated Local Search for Solving Capacitated Vehicle Routing Problems," 2016 International Symposium on Computer, Consumer and Control (IS3C), Xi'an, China, pp. 45-48, 2016.

[12] X. Zhengzheng, "A vehicle routing approach using mixed vehicles for pickup and delivery services to airport," The 27th Chinese Control and Decision Conference (2015 CCDC), Qingdao, China, pp. 6330-6334, 2015.

[13] A. R. Daanish and B. K. Naick, "Implementation of charging station based electric vehicle routing problem using nearest neighbour search algorithm," 2017 2nd IEEE International Conference on Intelligent Transportation Engineering, Singapore, Singapore, pp. 52-56, 2017.

[14] U. Lipowezky, et al., "Solving the Capacitated Open Vehicle Routing Problem Algorithm, Based on Probability Distribution Modelling of Saving Matrix," IEEE International Conference on the Science of Electrical Engineering in Israel (ICSEE), Eilat, Israel, pp. 1-5, 2018.

[15] Y. Hartono, et al., "LINGO-Based on Robust Counterpart Open Capacitated Vehicle Routing Problem (RC-OCVRP) Model of Waste Transportation in Palembang," 2018 International Conference on Information and Communications Technology (ICOIACT), Yogyakarta, pp. 429-435, 2018.

[16] F. M. Puspita, et al., "Model of Demand Robust Counterpart Open Capacitated Vehicle Routing Problem (DRC-OCVRP) Simplification by Applying Preprocessing Techniques in Rubbish Controlling in Sematang Borang District, Palembang," in E3S Web of Conferences, vol. 68, pp. 1-6, 2018.

[17] F. M. Puspita, et al., "Robust Counterpart Open Capacitation Vehicle Routing (RCOCVRP) Model in Optimization of Garbage Transportation in Sako District and Sukarami District, Palembang City," International Journal of Electrical and Computer Engineering (IJECE), vol. 8, no. 6, pp. 4382-4390, 2018.

[18] A. K. Ariyani, et al., "Hybrid Genetic Algorithms and Simulated Annealing for Multi-trip Vehicle Routing Problem with Time Windows," International Journal of Electrical and Computer Engineering (IJECE), vol. 8, no. 6, pp. 4713-4723, 2018.

[19] F. M. Puspita, et al., "Robust Counterpart-Open Capacitated Vehicle Routing Problem with Time Windows and Deadline (RC-OCVRPTWD) Model in Optimization of Garbage Transportation in Sub-District Kalidoni, Palembang using LINGO 13.0," 2nd International Conference on Science and Technology (ICST), Bengkulu, 2019. [Online], Available: http://semiratathe2ndicst.fmipa.unib.ac.id/.

[20] Y. Adulyasak and P. Jaillet, "Models and algorithms for stochastic and robust vehicle routing with deadlines," Transportation Science, pp. 1-19, 2015.

[21] X. Zhihui and F. Zhongning, "Study on emergency response of vehicle routing based on multi-commodity dispatch VRPTD model," in Proceedings 2011 International Conference on Transportation, Mechanical, and Electrical Engineering (TMEE), pp. 568-571, 2011.

[22] S. Sawadsitang, et al., "Optimal Stochastic Package Delivery Planning with Deadline: A Cardinality Minimization in Routing," 2017 IEEE 86th Vehicular Technology Conference (VTC-Fall), Toronto, ON, Canada, 2017.

[23] J. Sniezek and L. Bodin, "Cost models for vehicle routing problems," in 35th Hawaii International Conference on System Science, pp. 1403-1414, 2002.

[24] E. L. Solano-Charris, "Optimization Methods for the Robust Vehicle Routing Problem," Thesis, Universite De Technologie De Troyes, 2015.

[25] E. L. Solano-Charris, et al., "A robust optimization approach for the vehicle routing problem with uncertain travel cost," International Conference on Control, Decision and Information Technologies (CoDIT), Metz, France, pp. 098-103, 2014. 


\section{BIOGRAPHIES OF AUTHORS}
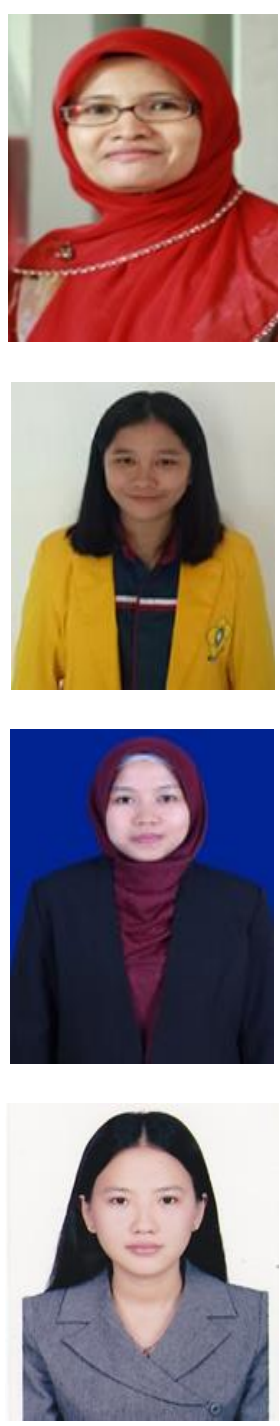

Fitri Maya Puspita received her S.Si degree in Mathematics from Sriwijaya University, South Sumatera, Indonesia in 1997. Then she received her M.Sc in Mathematics from Curtin University of Technology (CUT) Western Australia in 2004. She got her Ph.D from Faculty of Science and Technology Islamic Science University of Malaysia (USIM), Nilai, Negeri Sembilan Darul Khusus, Malaysia in 2015. She has been a Mathematics Department member at Faculty mathematics and Natural Sciences Sriwijaya University South Sumatera Indonesia since 1998. Her research interests include optimization and its applications such as vehicle routing problems and QoS pricing and charging in third generation internet.

Ani Sahara Br. Simanjuntak currently receives her S.Si degree in Mathematics from Sriwijaya University, South Sumatera, Indonesia in the beginning of year 2020. Her research interests focus on optimization problem especially on vehicle routing problem and its varian.

Rima Melati currently receives her S.Si degree in Mathematics from Sriwijaya University, South Sumatera, Indonesia in the beginning of year 2020. Her research interest focuss on optimization problem especially on vehicle routing problem and its varian.

Sisca Octarina received her S.Si degree in Mathematics from Sriwijaya University, South Sumatera, Indonesia in 2005. Then she received her M.Sc in Mathematics from Nanyang Technological University (NTU) in 2010. She has been a Mathematics Department member at Faculty mathematics and Natural Sciences Sriwijaya University South Sumatera Indonesia since 2006. Her research interests include optimization and its applications such as cutting stock problem vehicle routing problem and delay management. 